\title{
Erratum to: Separation of Molybdenum from Acidic High- Phosphorus Tungsten Solution by Solvent Extraction
}

\author{
YONGLI LI ${ }^{1}$ and ZHONGWEI ZHAO ${ }^{1,2,3}$ \\ 1.-School of Metallurgy and Environment, Central South University, Changsha 410083, China. \\ 2.-Key Laboratory of Hunan Province for Metallurgy and Material Processing of Rare Metals, \\ Changsha 410083, China. 3.—e-mail: zhaozw@csu.edu.cn
}

\section{Erratum to: JOM \\ DOI: $10.1007 / \mathbf{s 1 1 8 3 7 - 0 1 7 - 2 3 2 9 - 3}$}

The original publication of this article contained a few errors. Erroneous units added during production were removed from the sentence:
To explore the extraction of molybdenum and tungsten by TBP, experiments were carried out under conditions of initial $\mathrm{pH}$ values from 1.0 to 2.5 and $1 \mathrm{~mol} / \mathrm{L}$ phosphorus.

The original article was corrected. 